Additional X-ray Crystallographic Diagrams including displacement ellipsoid plots at the $50 \%$ probability level.

\title{
Compound 3a
}<smiles>CCCCCCCOc1c2c(c(OCCCCCC)c3sc4ccccc4c13)-c1ccccc1-2</smiles>

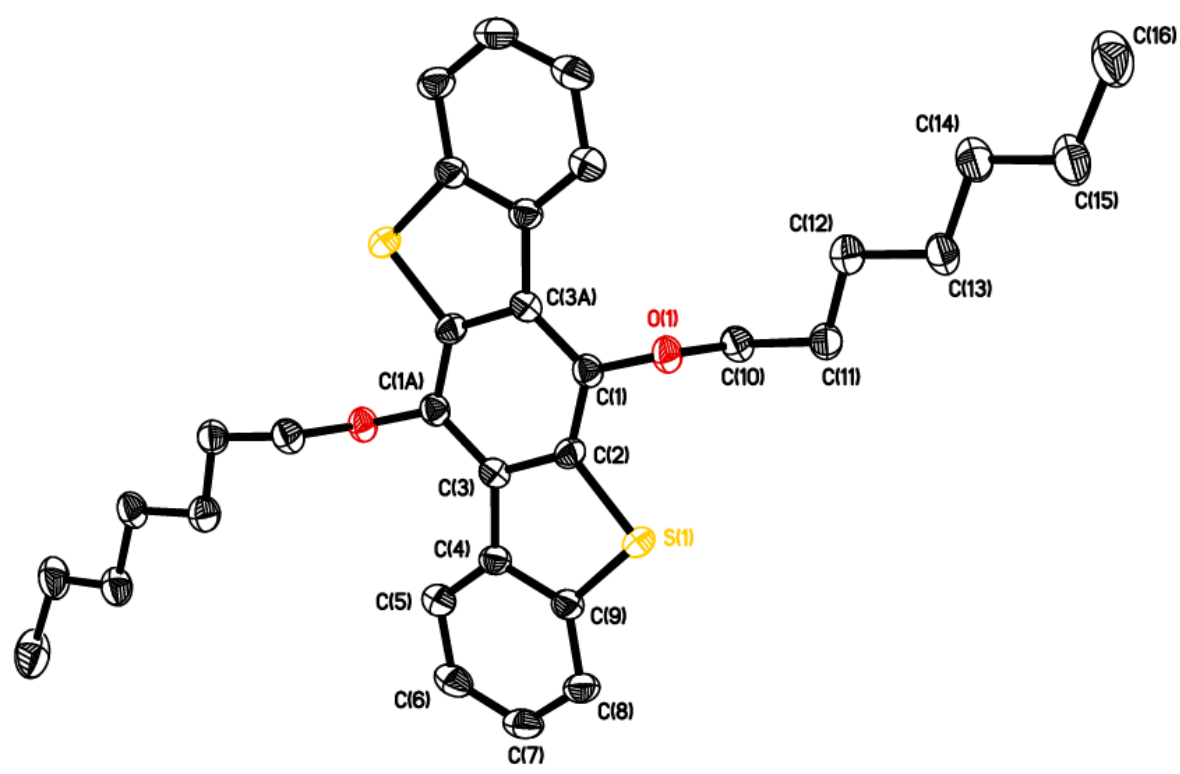




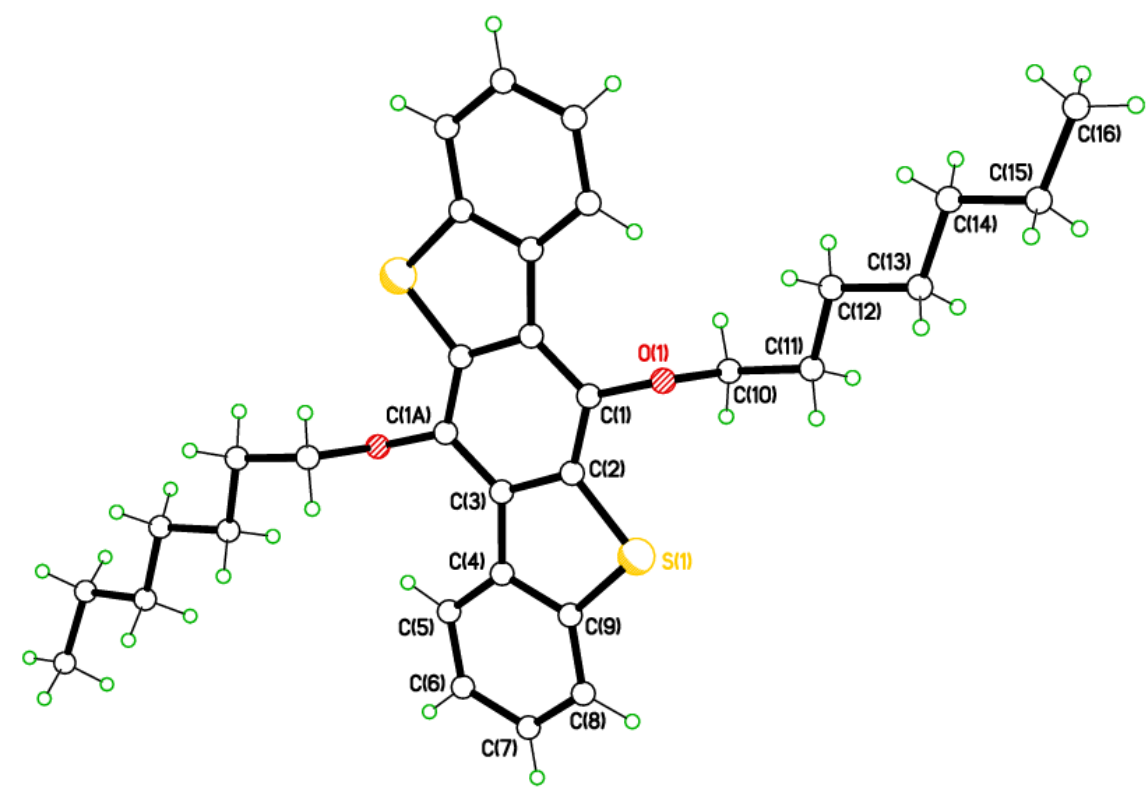

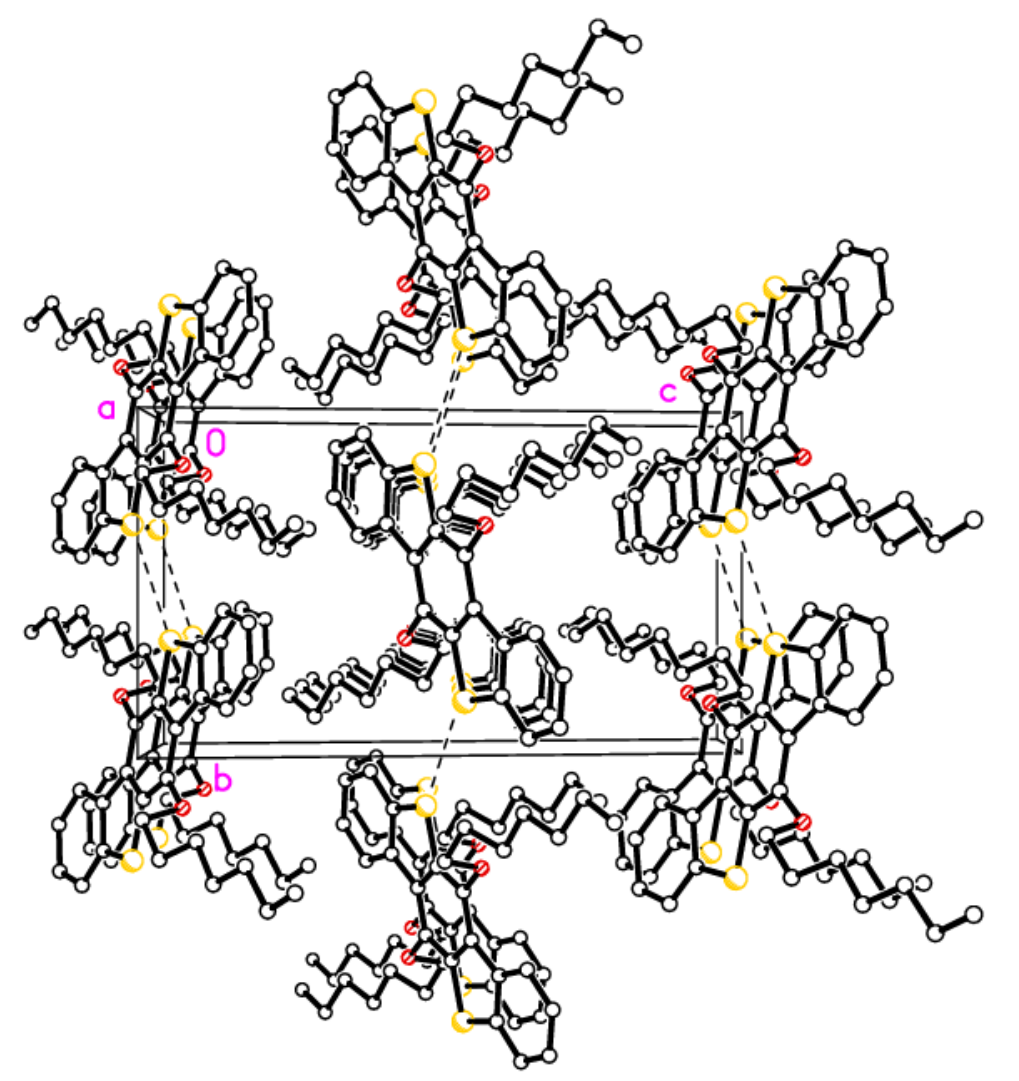



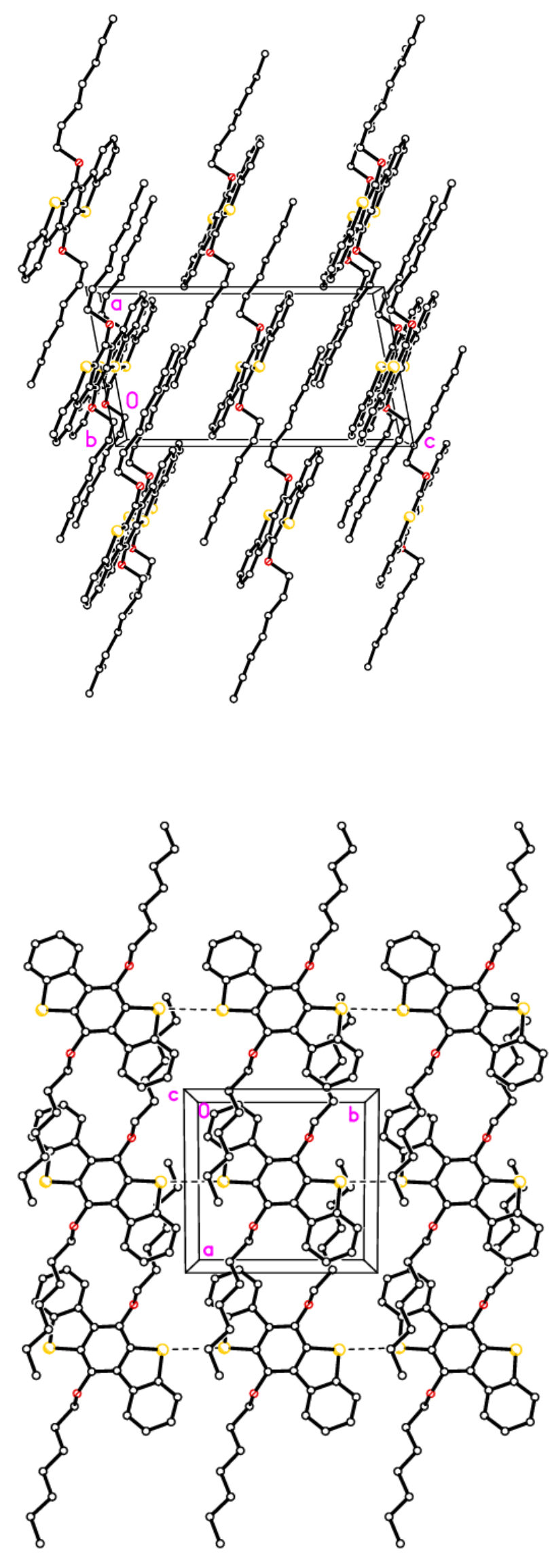


\section{Compound 3b}<smiles>CCCCCCCOc1c2sc3ccccc3c2c(OCCCCCCC)c2sc3ccccc3c12</smiles>
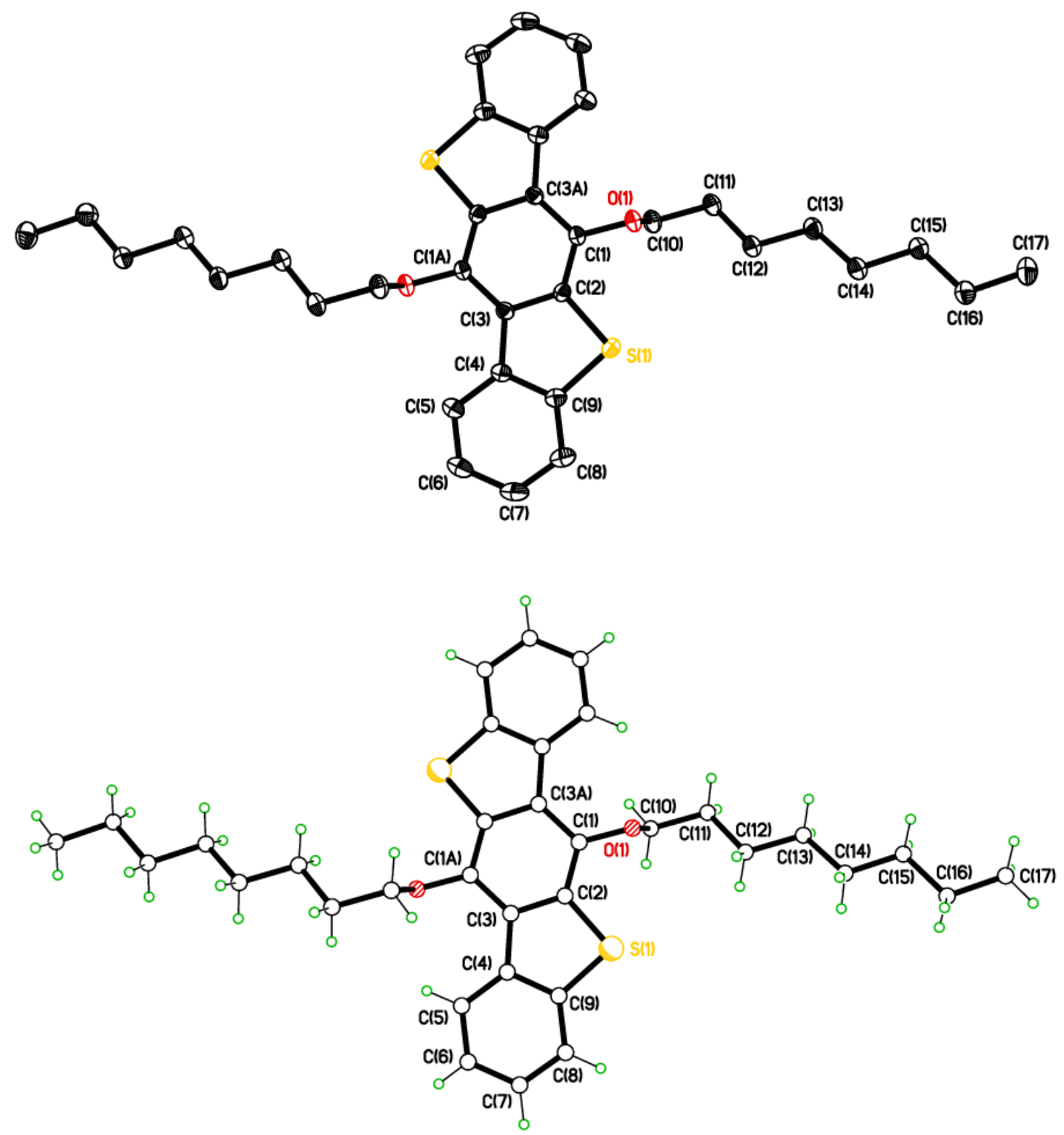

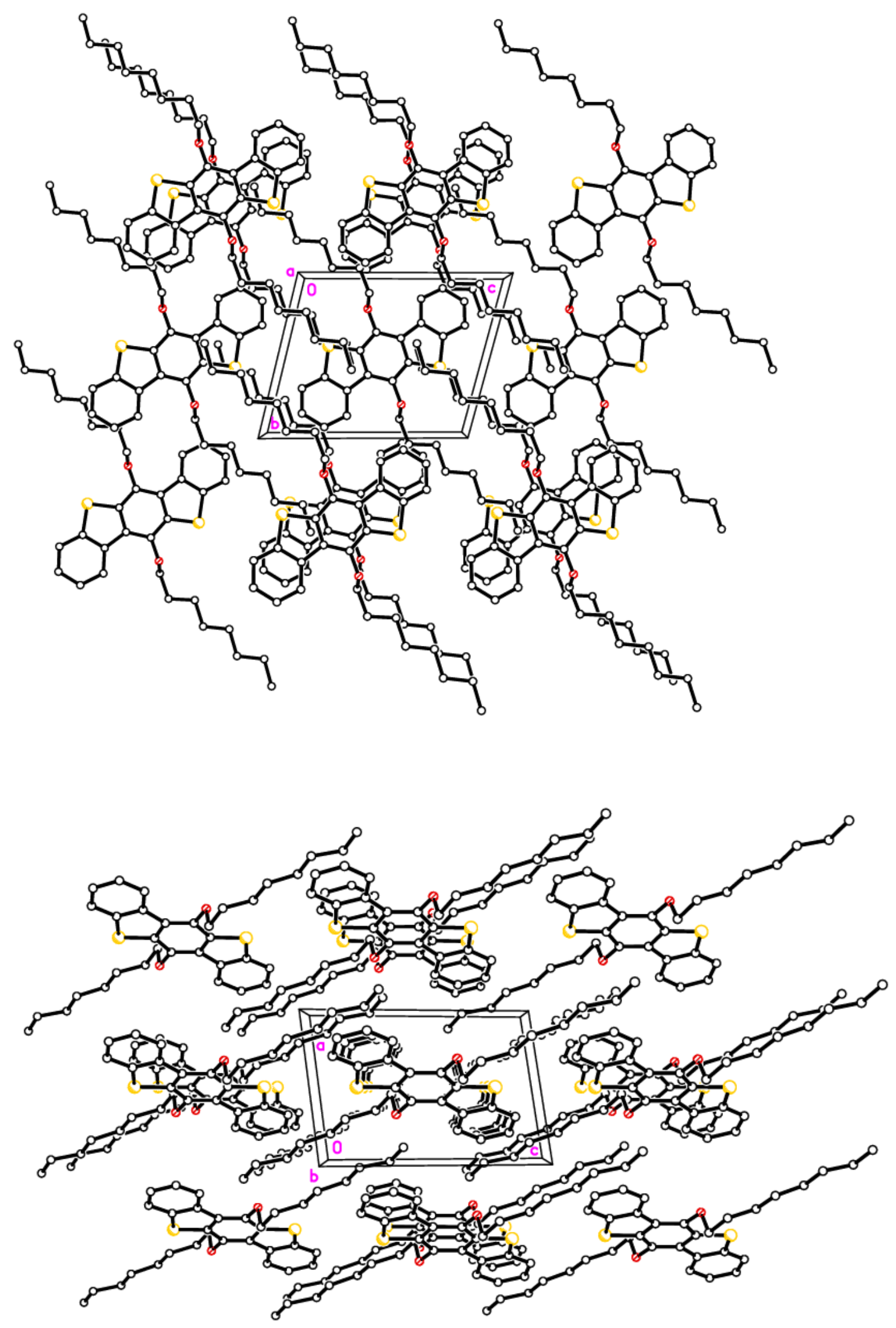


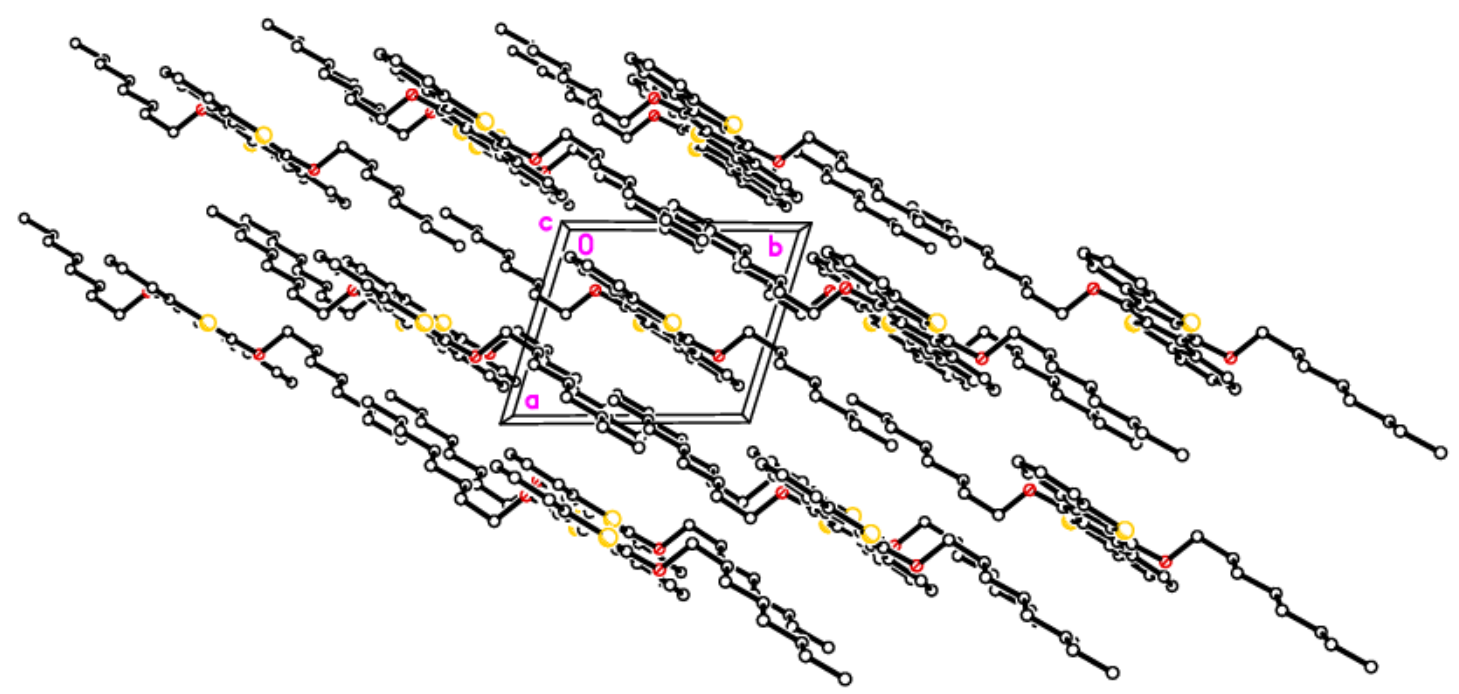




\section{Compound $3 \mathrm{c}$}

$\mathrm{C}_{9}$<smiles>CCCCCCCCCOC1=c2sc3ccccc3c2=C2C(OCCCCCCCCC)=c3sc4ccccc4c3=C12</smiles>

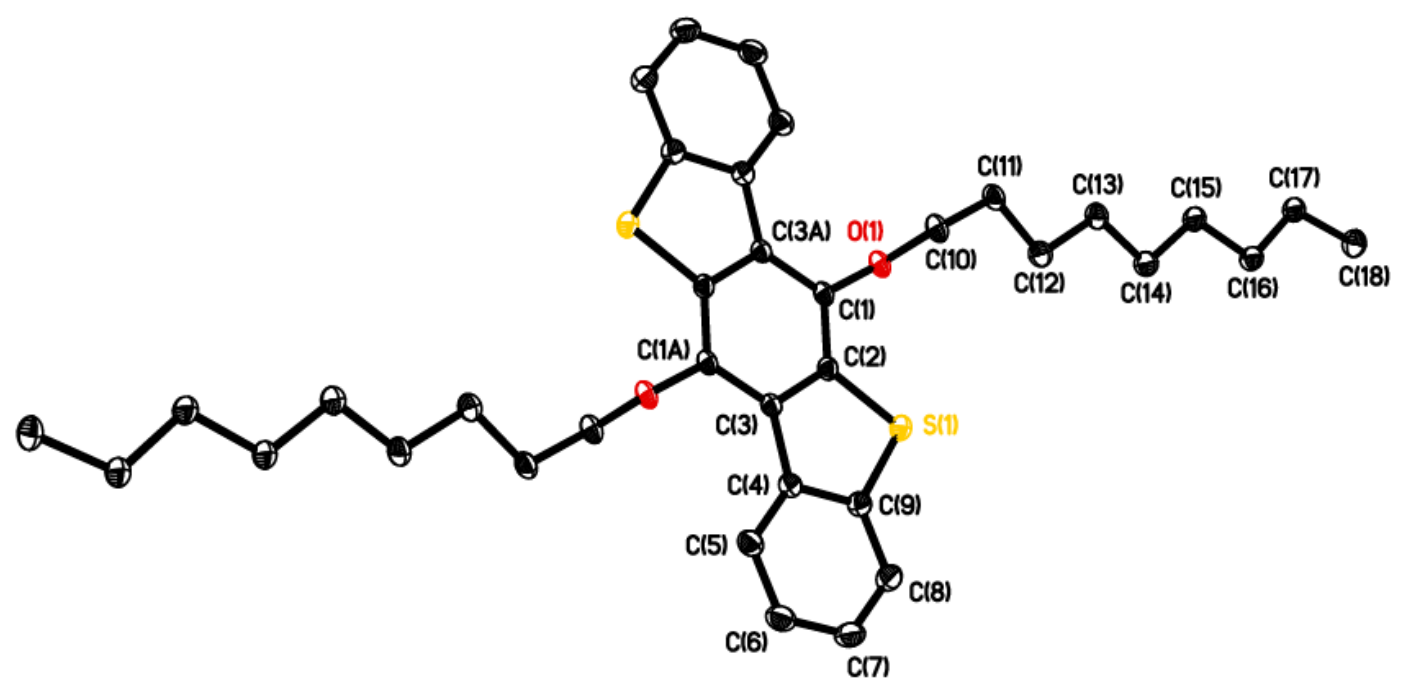

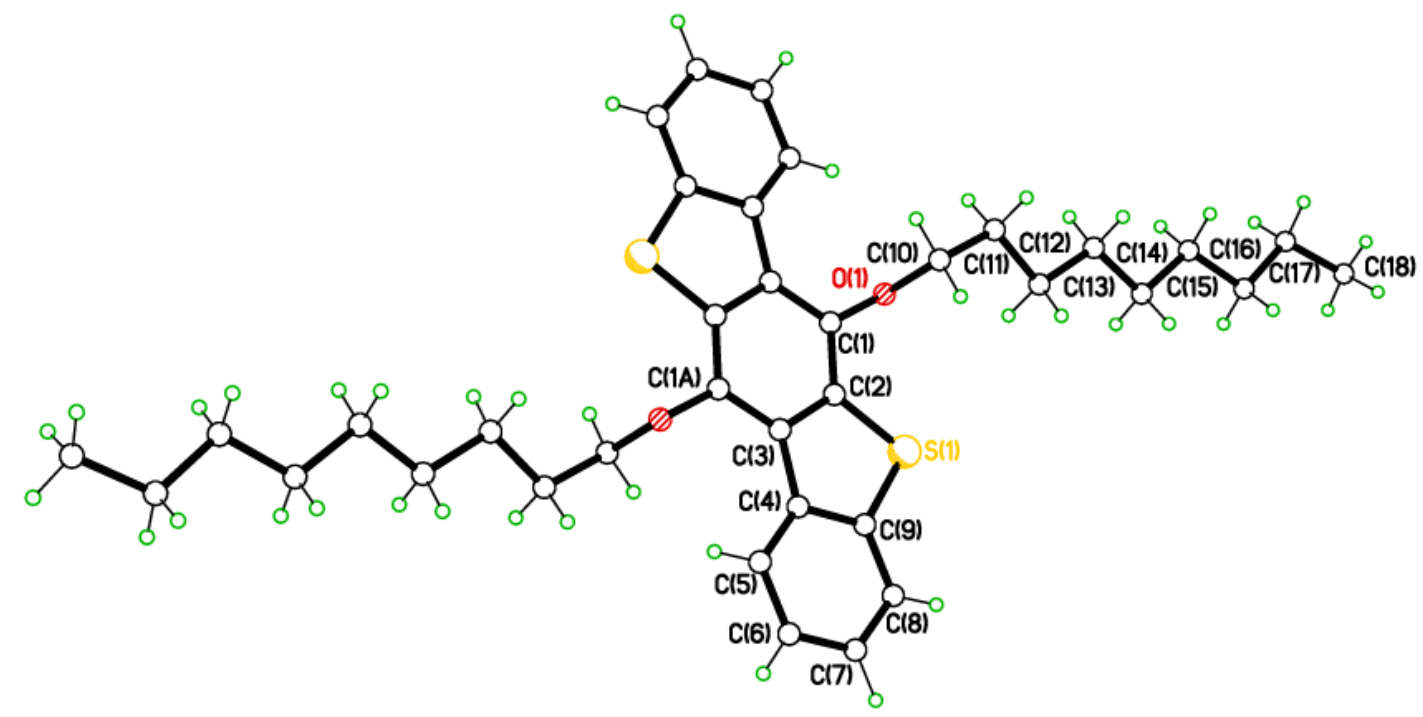



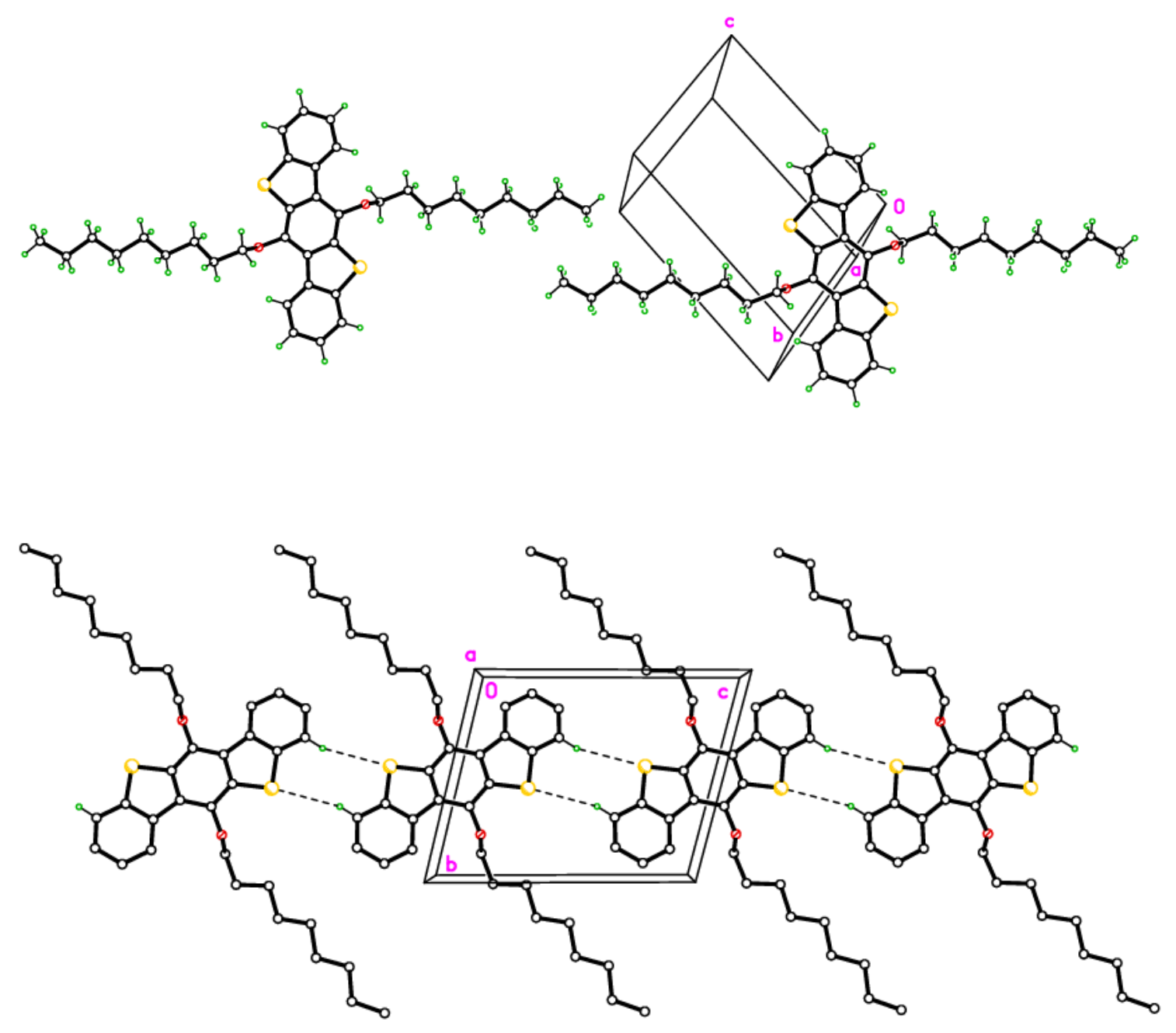


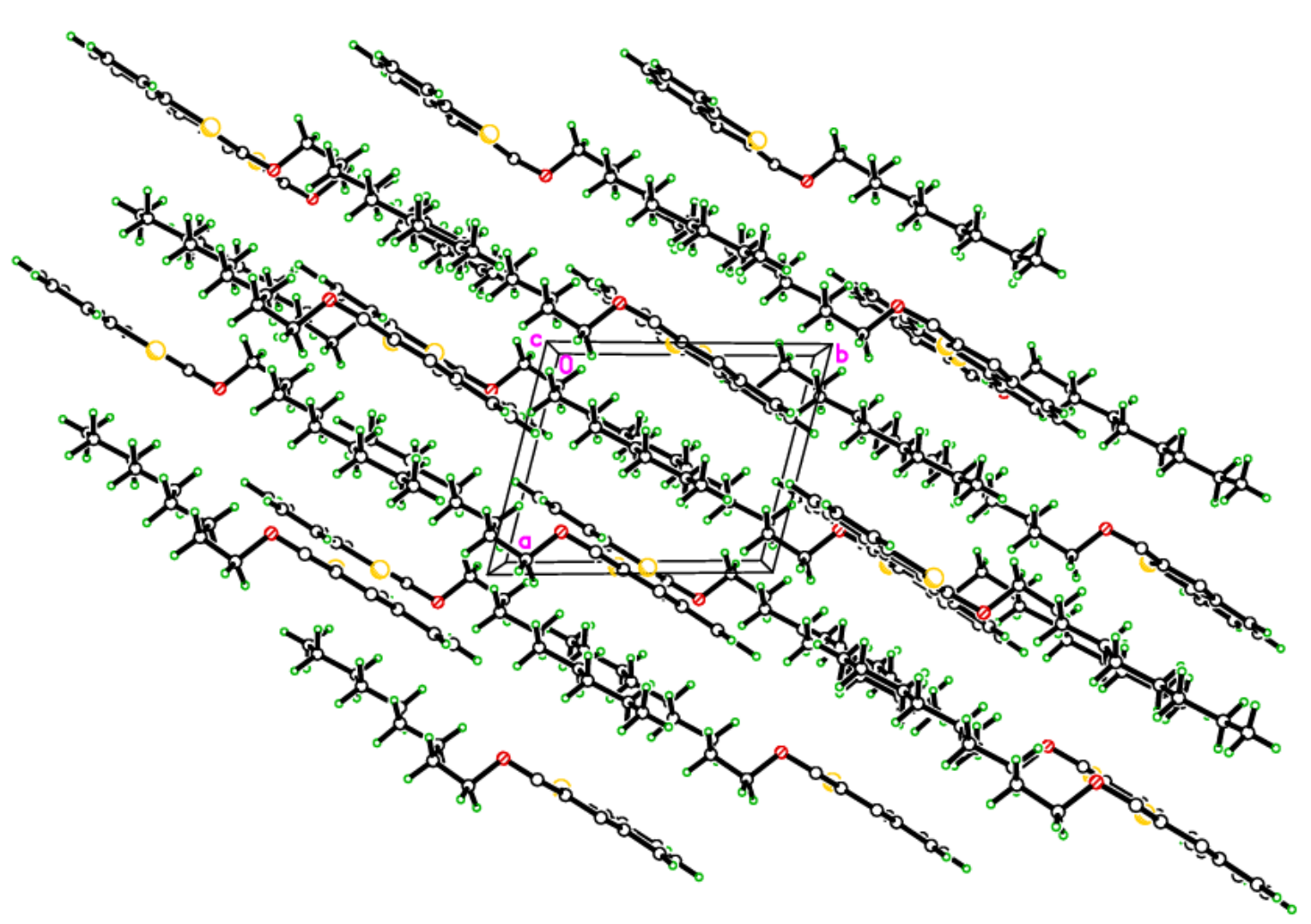




\section{Compound 3d}
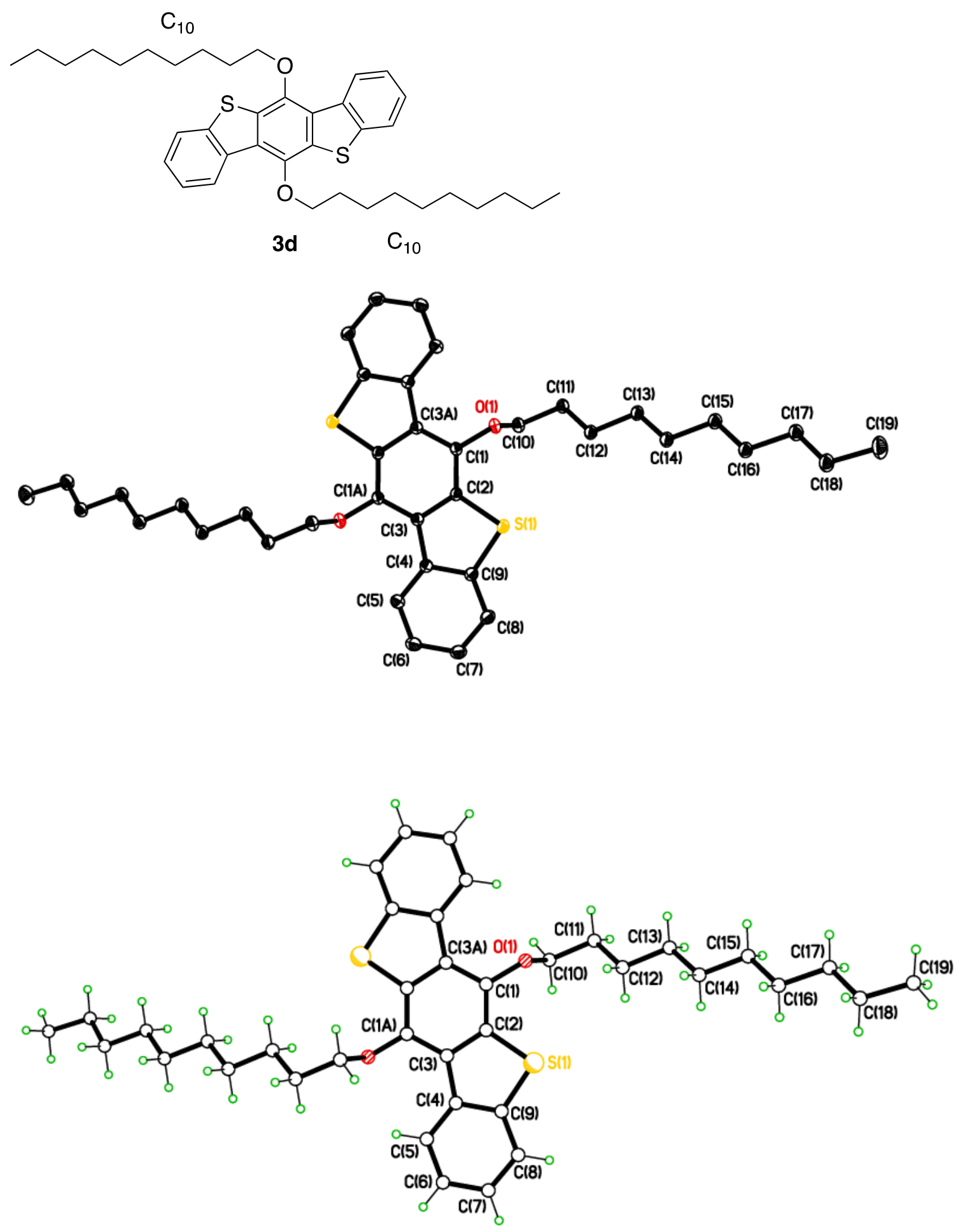


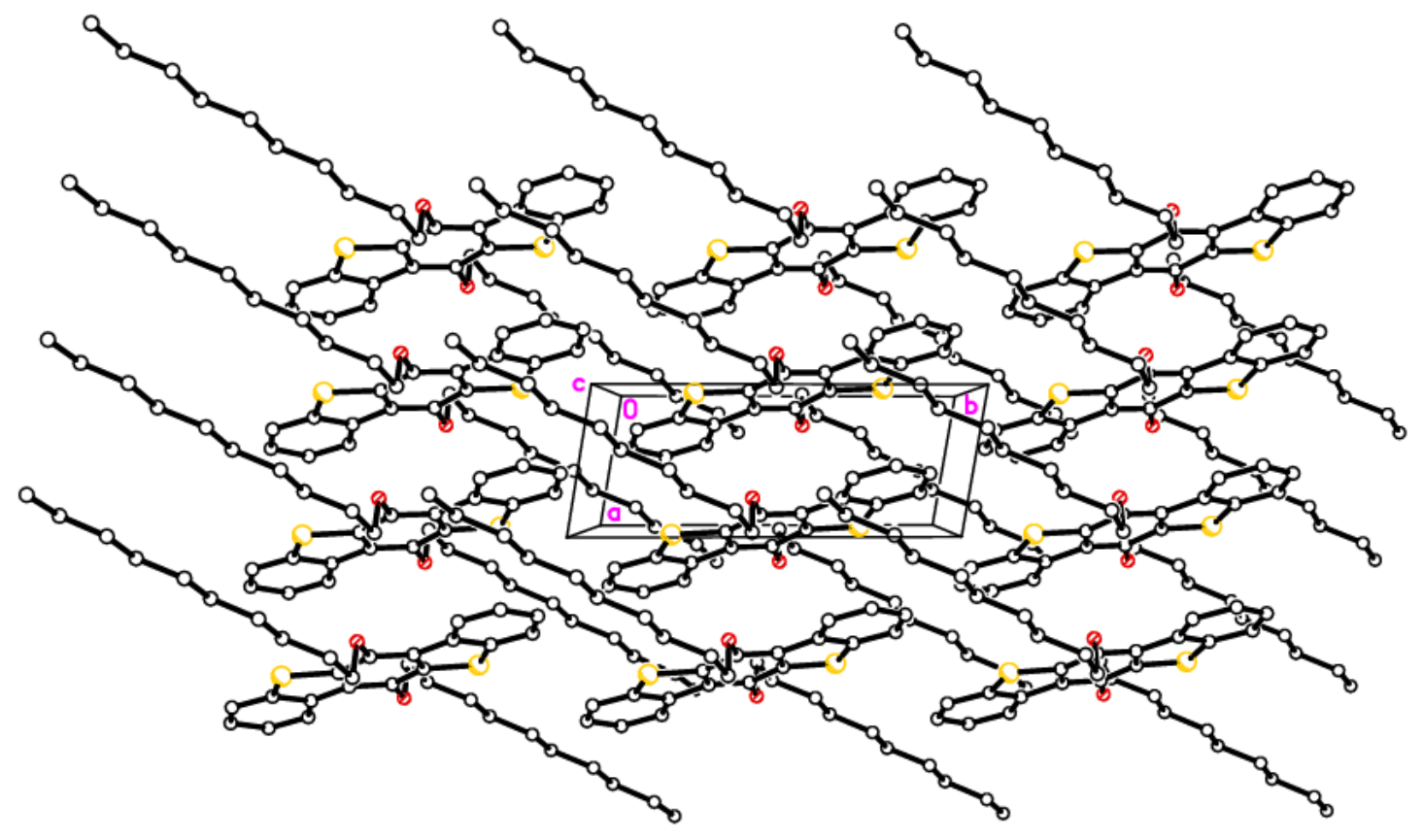


Compound $4 a$

$\mathrm{C}_{7}$<smiles>CCCCCCCSc1c2sc3ccccc3c2c(SCCCCCC)c2sc3ccccc3c12</smiles>

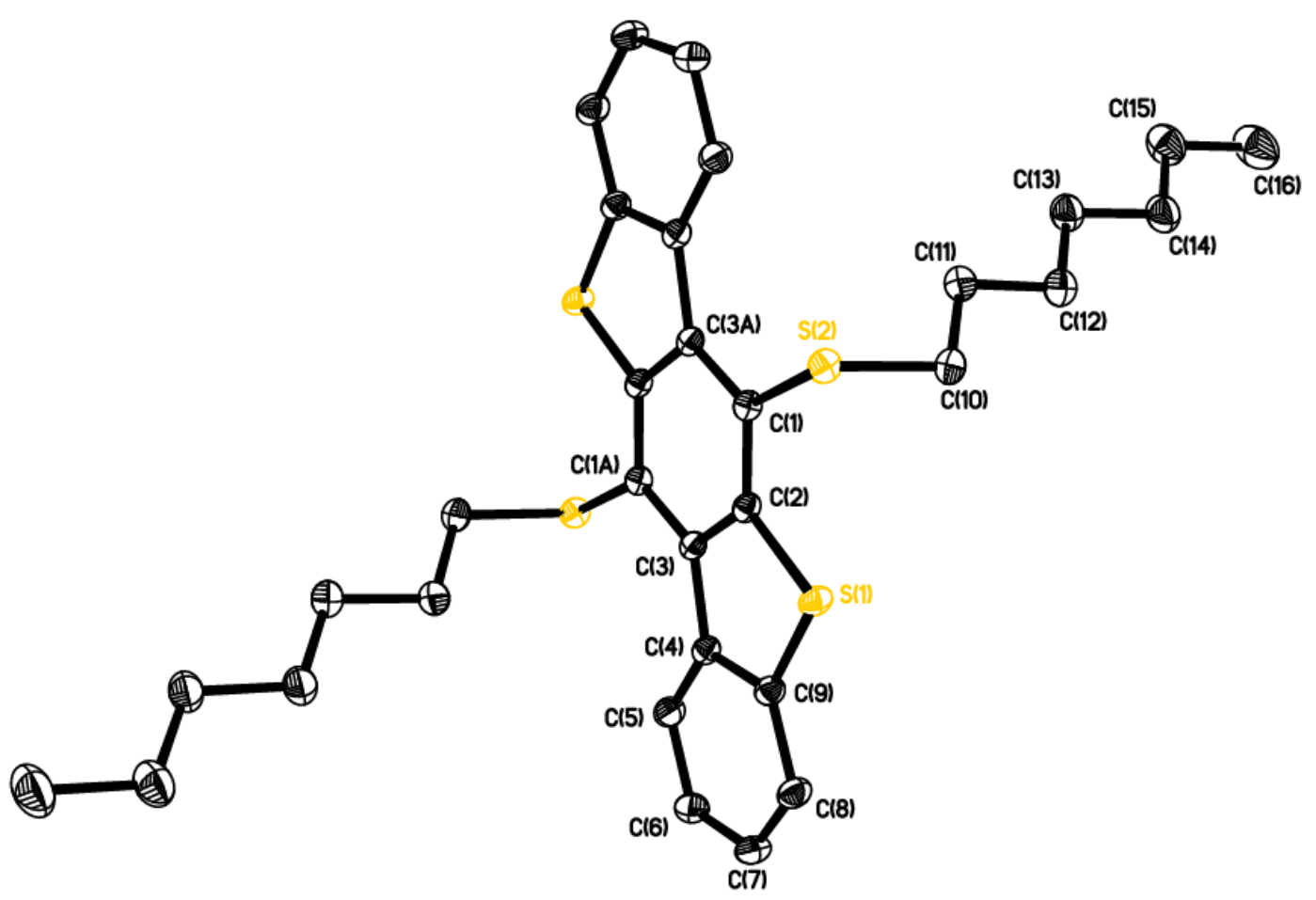



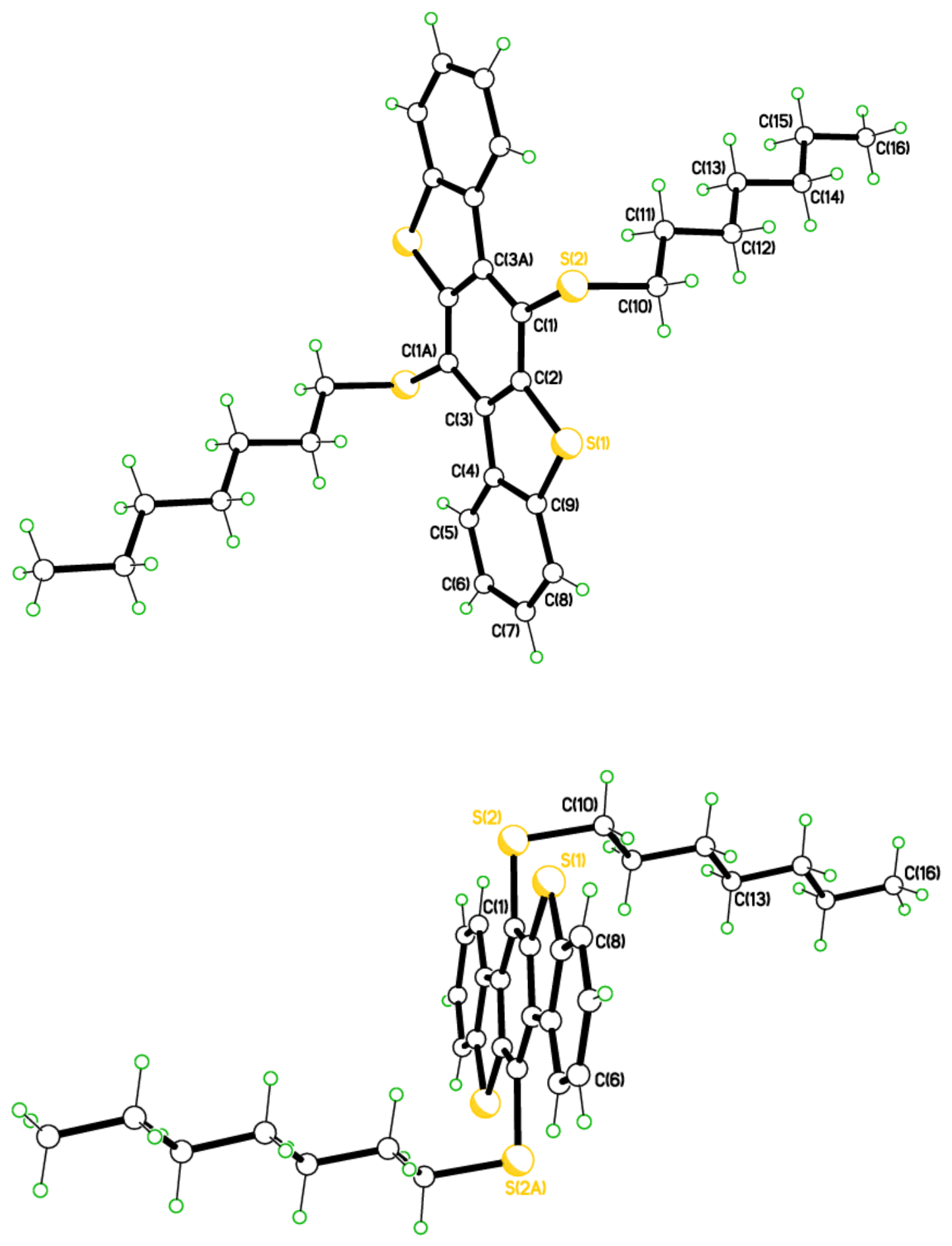


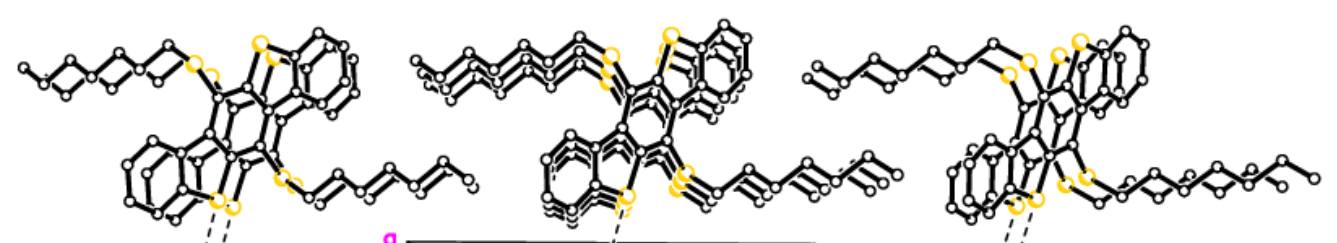

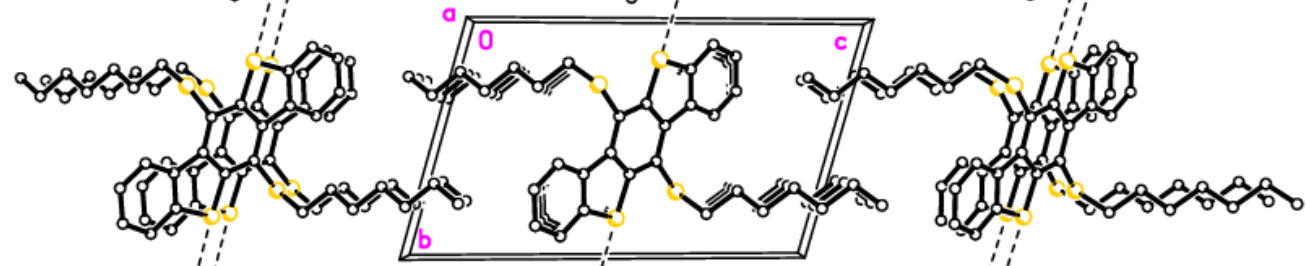

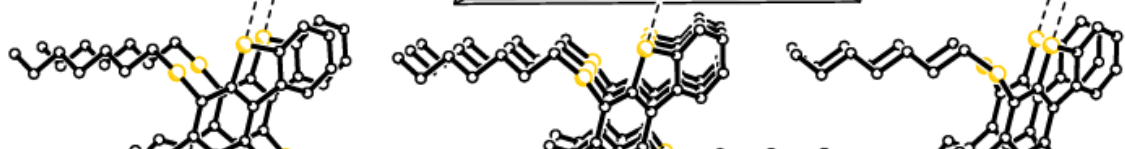
(2)

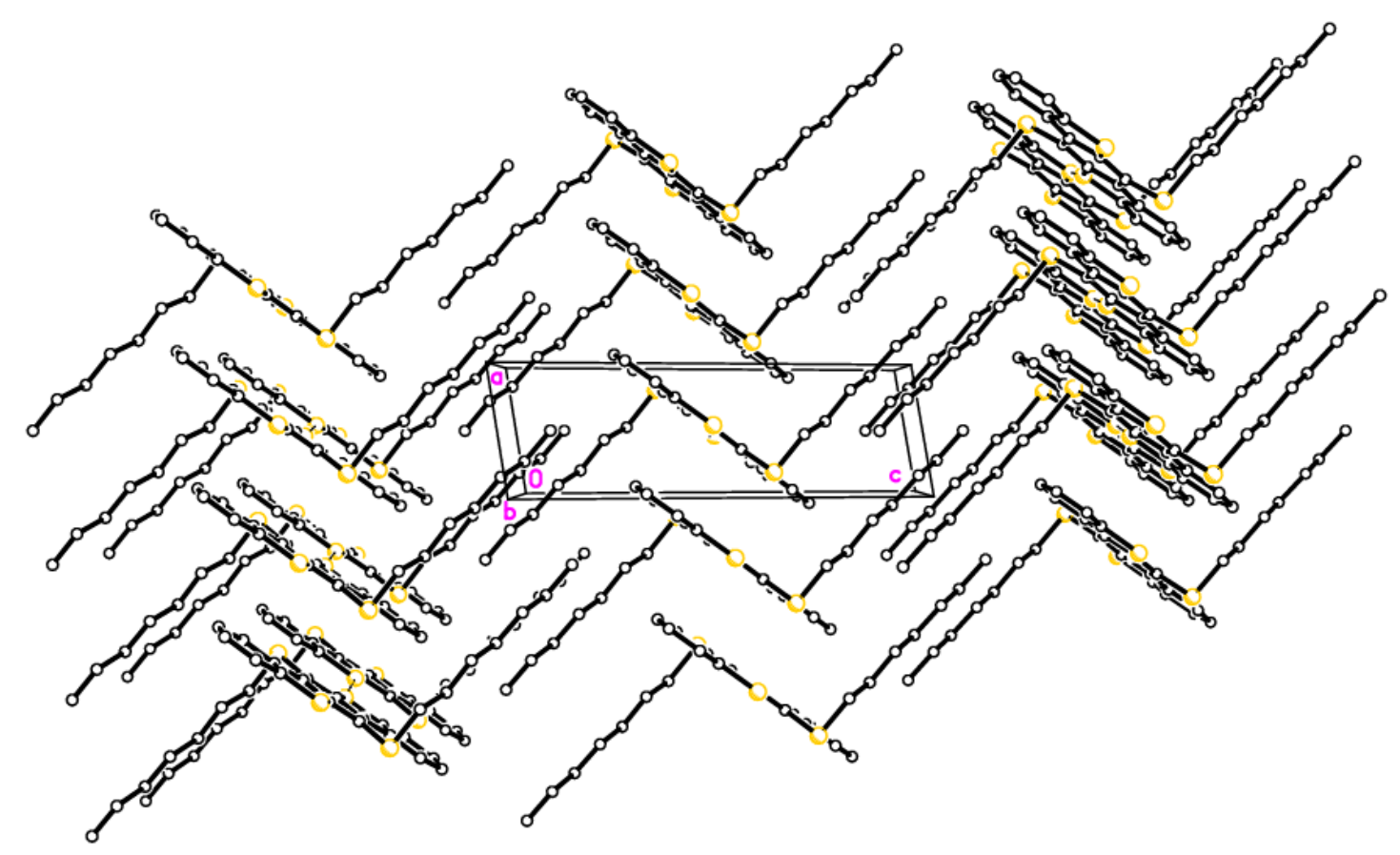




\section{Compound $4 \mathrm{~b}$}<smiles>CCCCCCCSc1c2sc3ccccc3c2c(SCCCCCCC)c2sc3ccccc3c12</smiles>
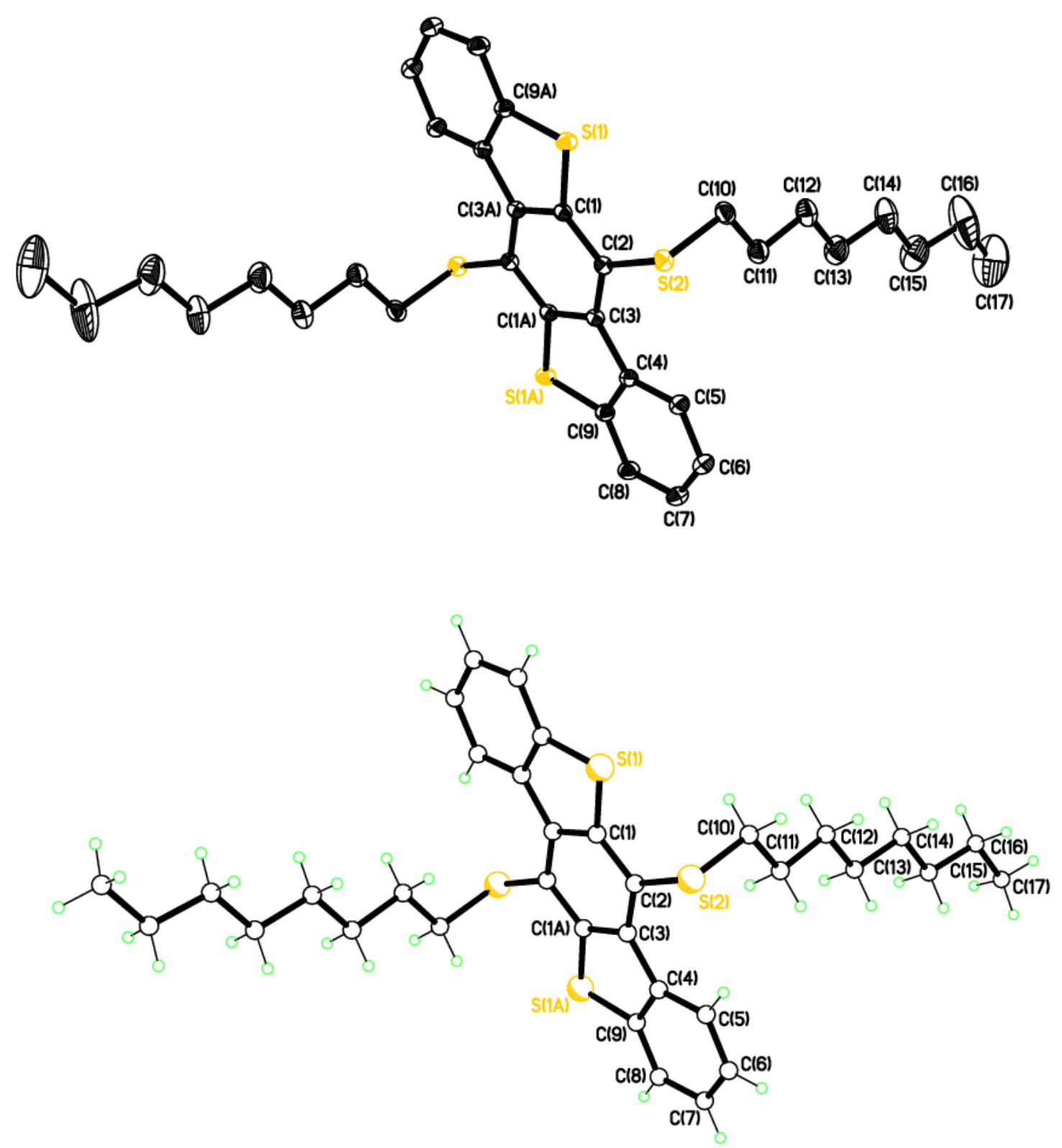

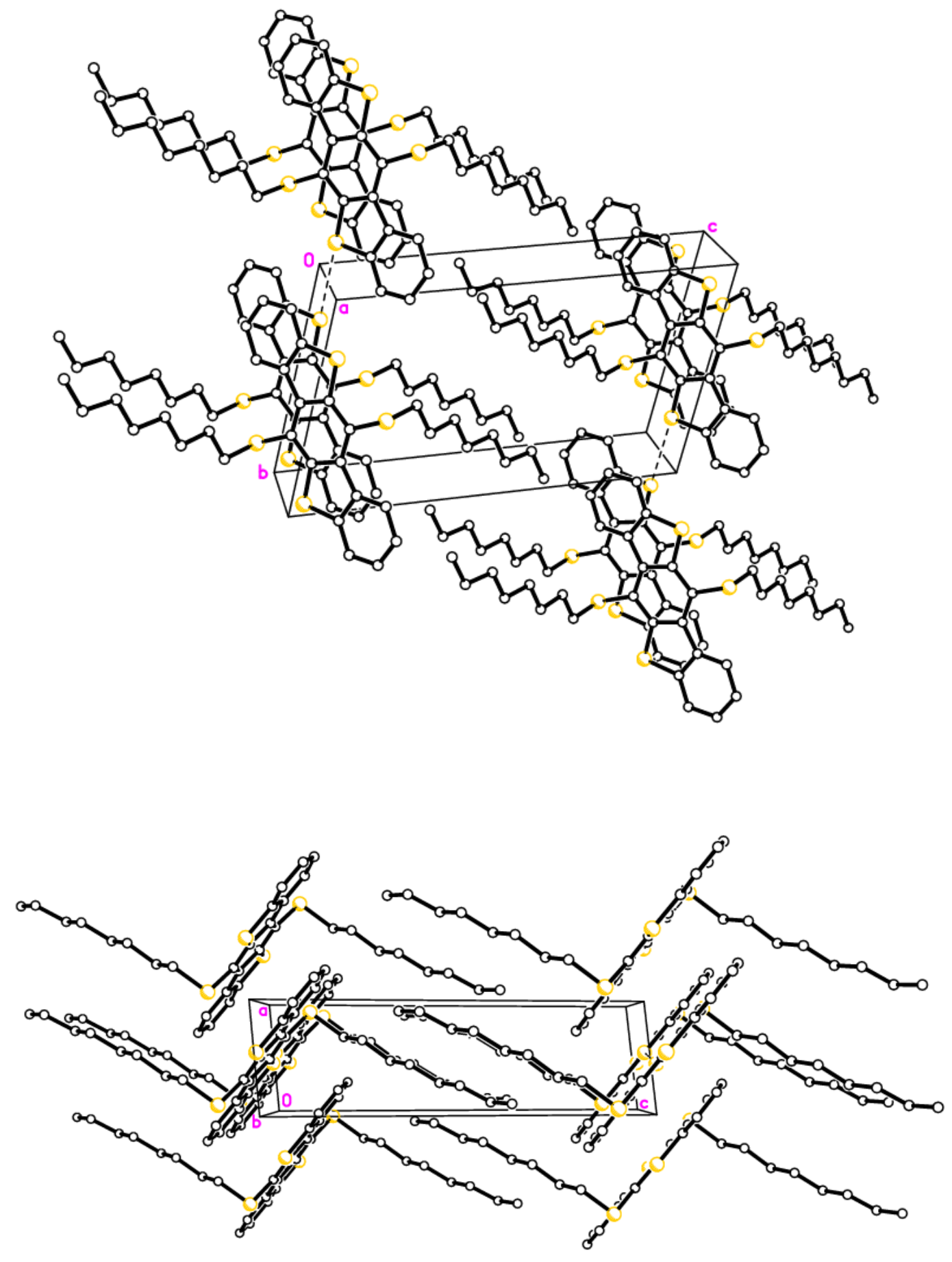


\section{Compound 4c}

$\mathrm{C}_{9}$<smiles></smiles>
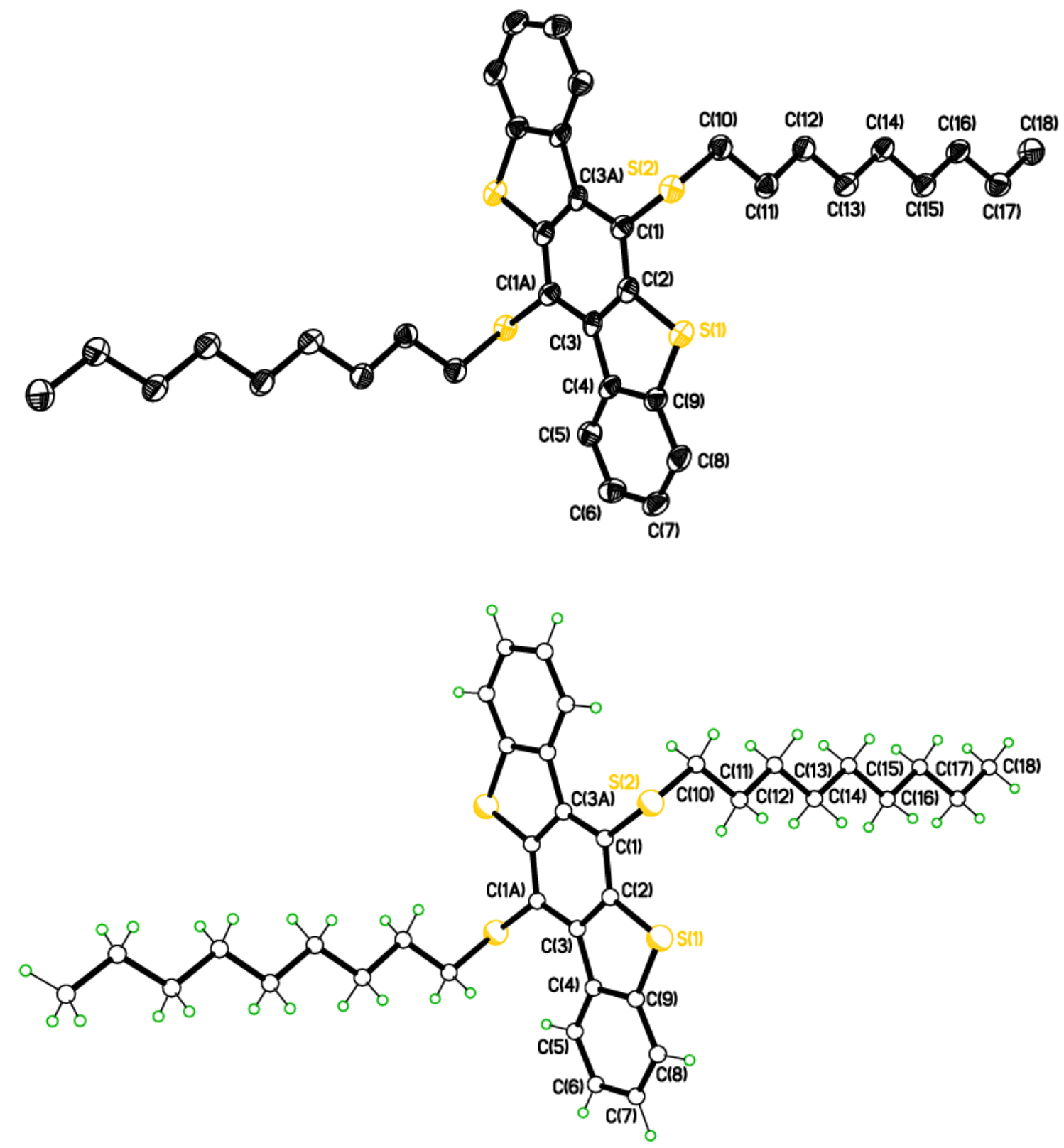

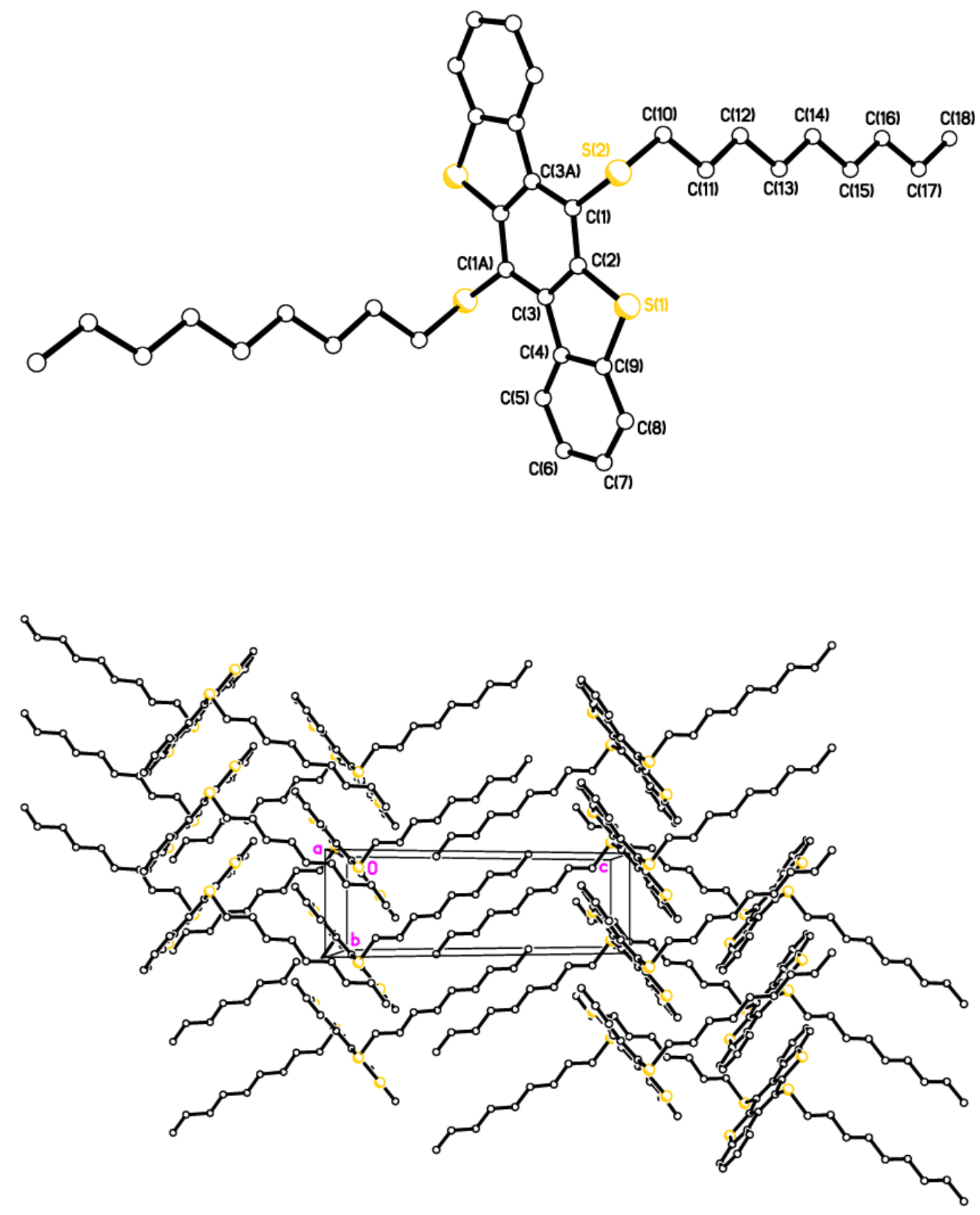

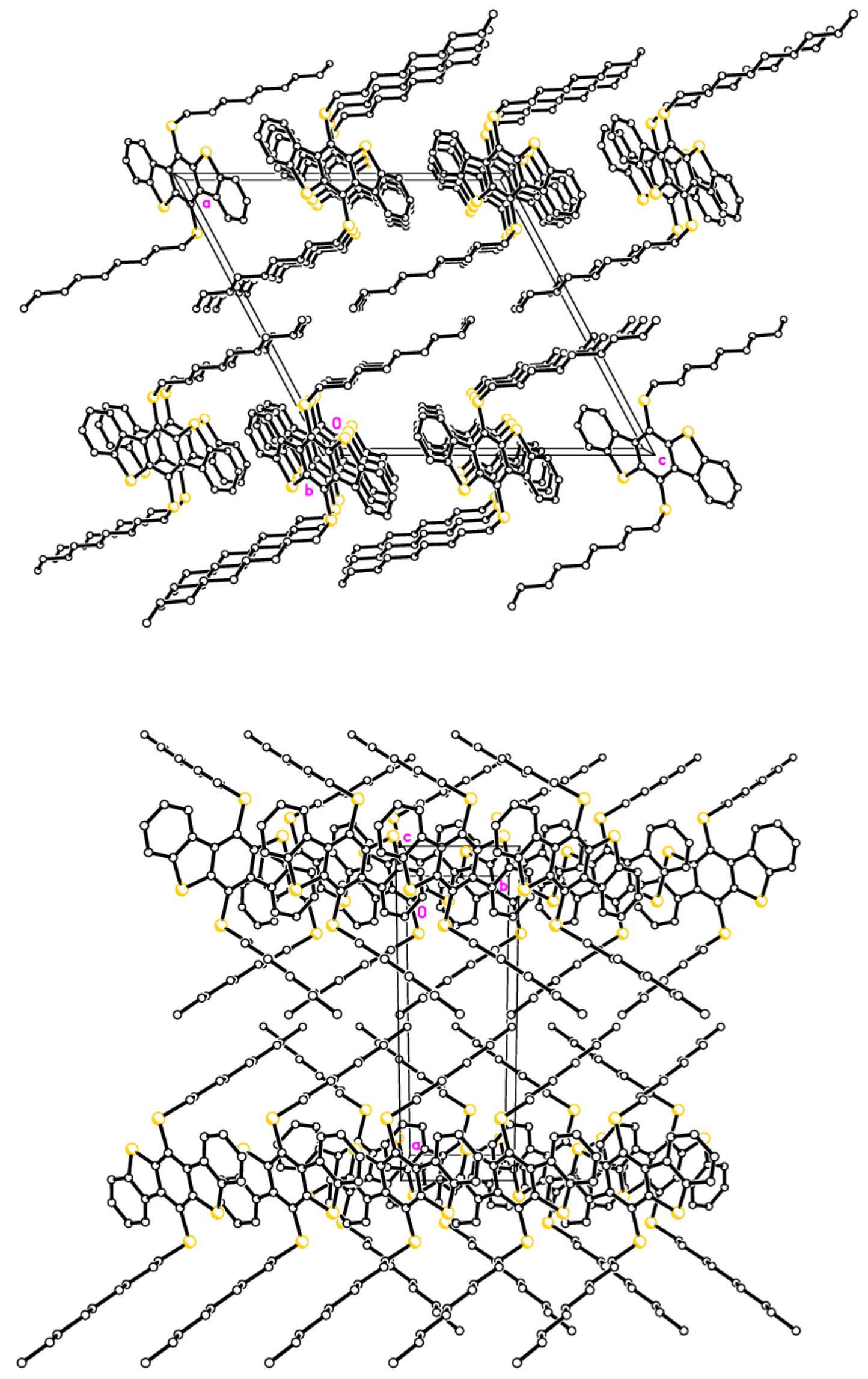


\section{Compound 4d}
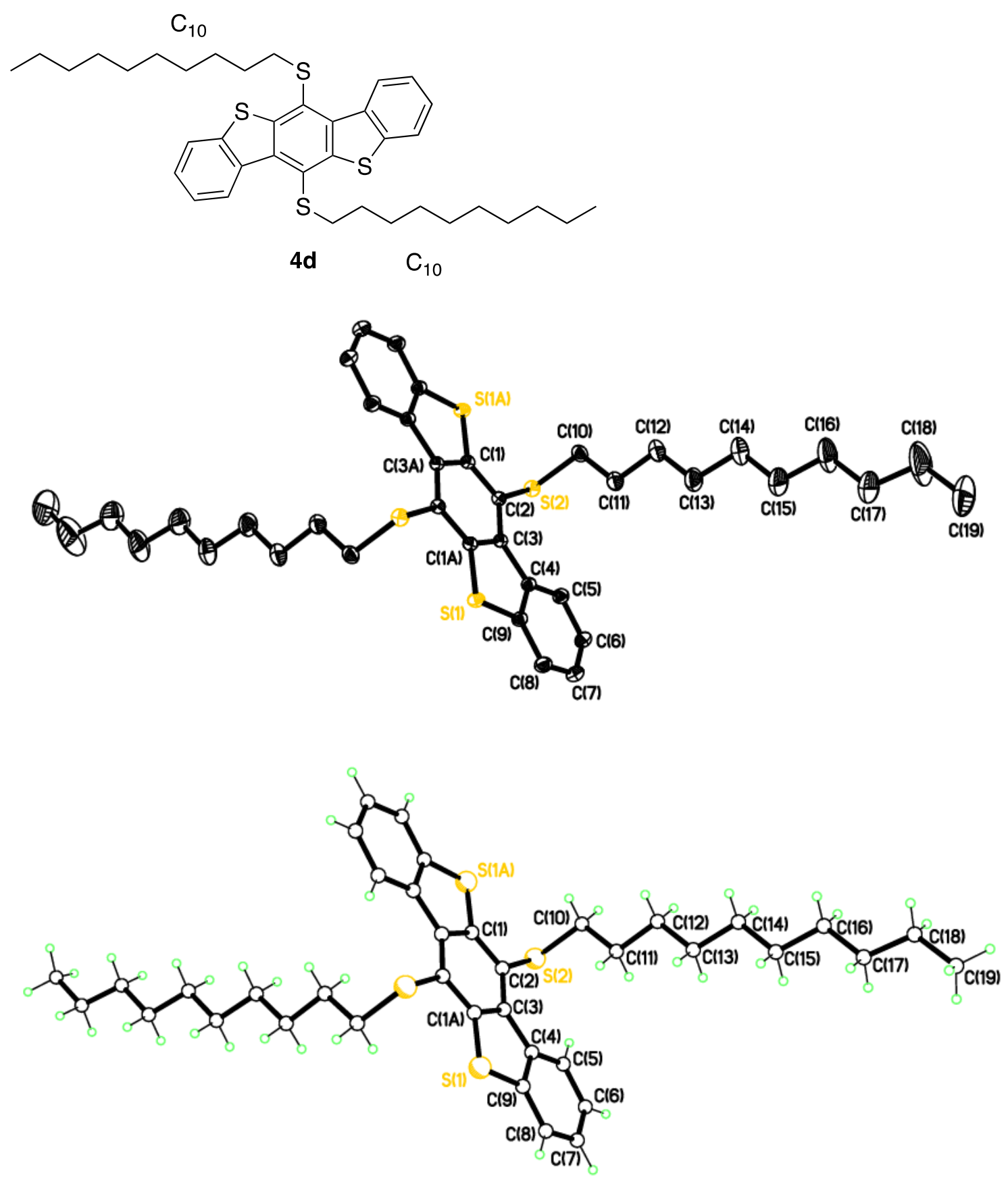


\section{Compound 5}<smiles>CCCCCCCOc1c2sc3ccccc3c2c(F)c2sc3ccccc3c12</smiles>
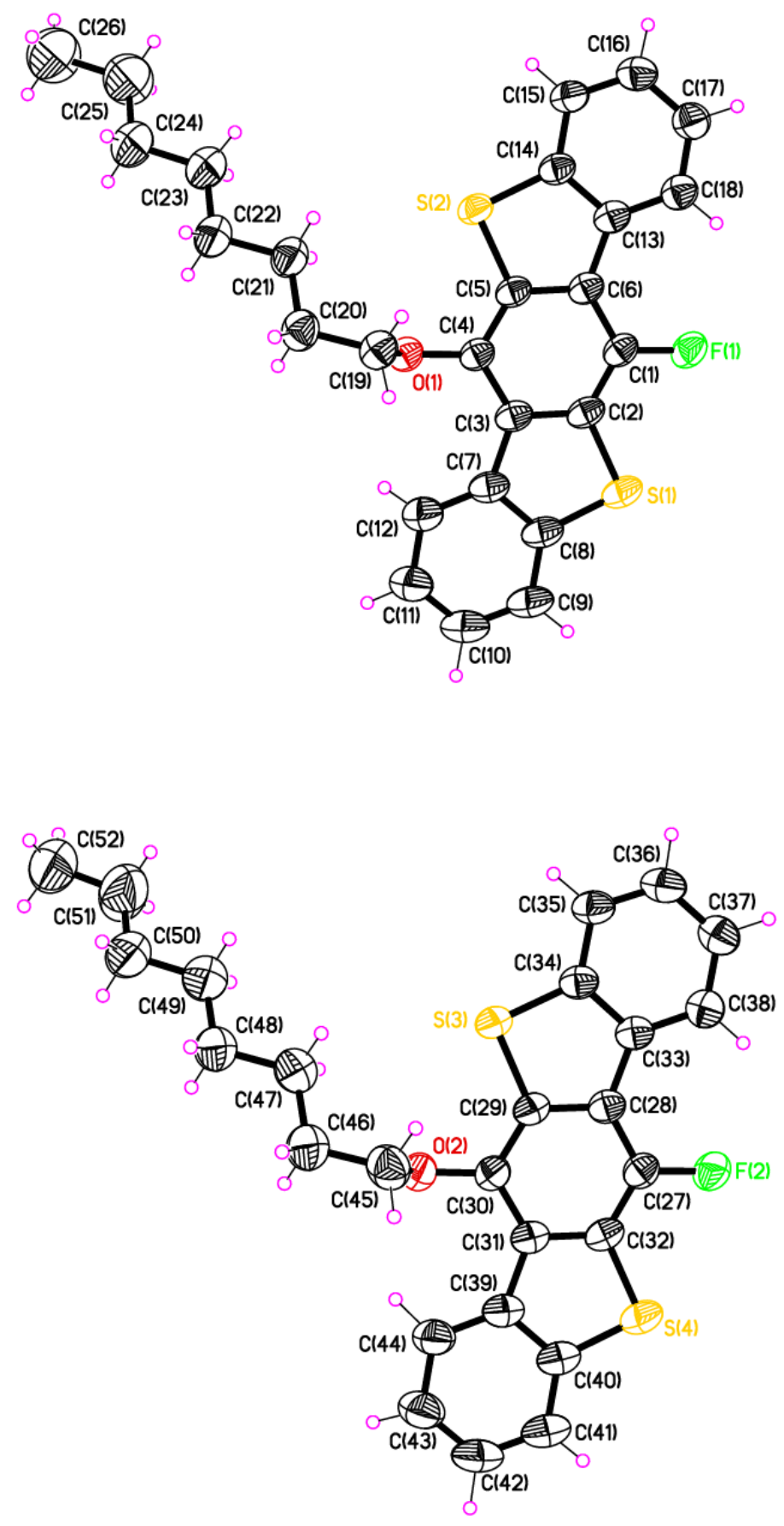

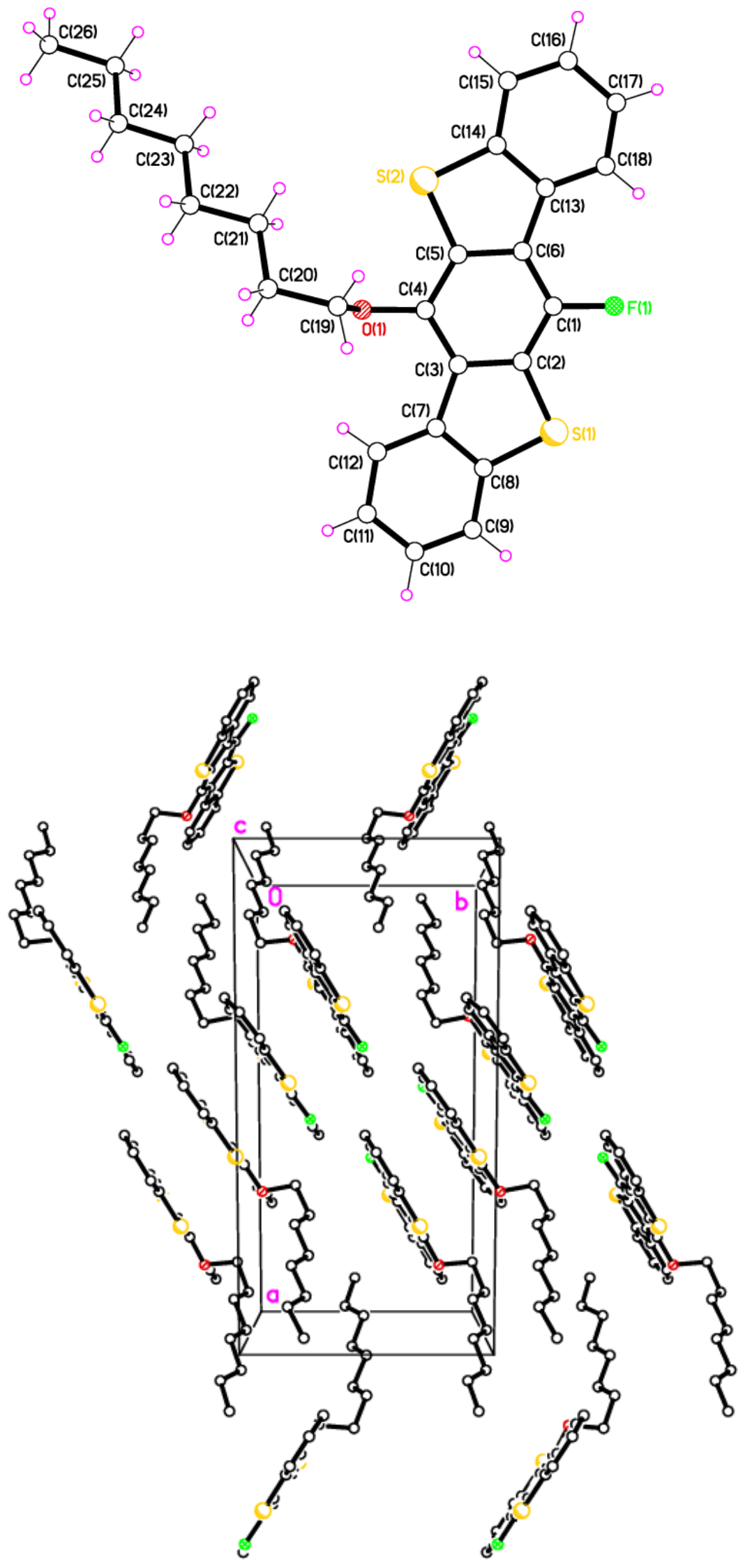